\title{
A Liturgia como ponto culminante da missão Uma breve leitura da Sacrosanctum Concilium 10 à luz da Evangelii Gaudium 24
}

\author{
Liturgy as the Culmination of Mission \\ A brief analysis of Sacrosanctum Concilium 10 in the light of Evangelii Gaudium 24
}

Diogo da Cunha Carvalho

\section{Resumo}

O presente artigo objetiva examinar a declaração, presente na Sacrosanctum Concilium 10, de que a liturgia é fonte e cume da vida da Igreja. Para tanto, pretende descortinar o sentido das duas analogias em sua relação com a missão da Igreja. Faz-se isso, primeiramente, por meio de um sintético apanhado do que já se comentou sobre o tema em alguns textos celebrativos da Constituição Litúrgica e, depois, por meio do cotejo com o Magistério do Papa Francisco, em especial a Evangelii Gaudium 24. Busca-se verificar também de que forma a analogia da fonte e cume, examinada à luz da referida Exortação Apostólica, parece sugerir que uma participação mais qualitativa e quantitativa dos fiéis na liturgia pode estar condicionada, em grande medida, a uma maior e melhor participação deles na missão cristã cotidiana. Ao final, propõe-se que, dada essa estreita relação entre a participação na liturgia e a participação na missão, à completa implementação dos ideais vislumbrados pelo Concílio Vaticano II pressupõe o auxílio mútuo entre missiologia e teologia litúrgica, missão e liturgia.

Palavras-chave: Liturgia. Participação. Vaticano II. Francisco. Missiologia.

\begin{abstract}
This article aims to examine the Sacrosanctum Concilium 10 declaration that says that Liturgy is the source and summit of Church's life. To do so, it intends to uncover the meaning of the two analogies in their relationship with the mission of the Church. First, the article aims to do this through a synthetic analysis of what some celebratory texts of the Liturgical Constitution has already commented on this subject in. Second, it will do this by comparing the Sacrosanctum Concilium 10 with the Magisterium of Pope Francisco, especially the Evangelii Gaudium. The article also intends to verify how the analogy of the source and summit, examined in the light of the aforementioned Apostolic Exhortation, seems to suggest that a more qualitative and quantitative participation of the faithful in the liturgy may be largely conditioned to a greater and better participation in the everyday Christian mission. Finally, the article propose that, once this close relationship between the participation in the liturgy and the participation in the Mission is verified, the complete implementation of the Second Vatican Council depends on the mutual contribution between missiology and liturgical theology, mission and liturgy.
\end{abstract}

Keywords: Liturgy. Participation. Vatican II. Pope Francis. Missiology. 


\section{Introdução}

Quando os padres conciliares formulavam o número 10 da Sacrosanctum Concilium, segundo o qual "a liturgia é o cume para o qual tende a ação da Igreja e, ao mesmo tempo, é a fonte donde emana toda a sua força", ${ }^{1}$ estavam, na verdade, compondo um refrão que, dada sua beleza e exatidão, seria exaltado quase sempre que se referisse ao documento nas décadas que se seguiram. Com frequência, as metáforas do cume e da fonte têm sido empregadas para ilustrar o espírito da renovação litúrgica propugnada pelo Concílio Vaticano II. Pelo menos três textos elaborados em datas comemorativas recordam a referida analogia.

$\mathrm{Na}$ conclusão da Carta Apostólica Vicesimus quintus annus, alusiva aos vinte e cinco anos da Constituição, João Paulo II reafirma tais comparações e esclarece seu sentido. ${ }^{2}$ Aos quarenta anos da promulgação do documento, Piero Marini, não apenas relembra as metáforas, como as considera um "ditado teológico real". ${ }^{3}$ Dez anos mais tarde, Alberto Beckhäuser, em edição comemorativa do cinquentenário da Constituição, vale-se das mesmas figuras para discorrer sobre a essencialidade da liturgia na vida da Igreja. ${ }^{4}$

Mas, o que significa dizer que a liturgia é cume e fonte da vida da Igreja? Quais os contornos dessa expressão, reconhecida como preceito teológico real (Marini), e não mera retórica ou modismo? ${ }^{5}$ E que relação ela guarda com a missão da Igreja? Longe de esgotar o tema, este artigo esboça uma possível resposta a essas questões, para, ao final, suscitar uma provocação à luz do Magistério do Papa Francisco sobre as implicações da estreita relação havida entre a participação na liturgia e a participação na missão evangelizadora.

\section{A liturgia como cume e fonte da vida da Igreja (SC 10)}

De início, note-se que cume e fonte são metáforas de cunho geográfico. O cume (ou pico) alude ao ponto mais elevado de um monte, ou, figurativamente, ao auge ou clímax de algum processo. Fonte, por sua vez, remete ao manancial no solo de onde brota água ou, em linguagem abstrata, à origem ou procedência de alguma coisa.

Embora denotem lugar, as duas palavras, usadas de maneira figurativa, revelam uma dimensão temporal que as torna contrastantes entre si. Cume pressupõe algo anterior, uma preparação que evolui para um clímax. Fonte induz um tempo posterior; nela, aquilo que está oculto vem à tona, para então se dinamizar.

Dessa forma, ao caracterizar a liturgia como cume e fonte, a Constituição Litúrgica parece compreendê-la um ponto tanto de partida quanto de chegada de alguma coisa. Como salienta Puebla, a liturgia "se dá em um determinado tempo e espaço, mas compreende também um antes e um depois". ${ }^{6}$ Detenha-se um pouco sobre como essa dupla temporalidade (antes e depois) tem sido explorada em alguns documentos que repercutem a Sacrosanctum Concilium.

\subsection{A Liturgia como ponto de partida (fonte)}

Segundo o parágrafo 10 do documento, o efeito do qual a liturgia se apresenta como fonte é a força da Igreja ("fonte donde emana toda a sua força"). Um parágrafo antes, a Constituição consignara que "a Sagrada Liturgia não esgota toda a ação da Igreja". ${ }^{7}$ Por assim dizer, a liturgia abastece a Igreja de força justamente para o desempenho de sua multiforme ação, que extrapola a liturgia. A liturgia é

\footnotetext{
${ }^{1} \mathrm{SC} 10$

2 VQA.

${ }^{3}$ MARINI, P., Quarantième anniversaire de la Constitution conciliaire sur la Liturgie.

${ }^{4}$ BECKHÄUSER, A., Sacrosanctum Concilium, p. 11.

${ }^{5}$ COMISSÃO EPISCOPAL PARA A LITURGIA, Liturgia e Evangelização, n. 2.

${ }^{6} \mathrm{DP} 938$.

${ }^{7} \mathrm{SC} 9$.
} 
fonte porque, saciando os fiéis por meio dos sacramentos pascais, impele-os à prática da piedade, à conservação da fé e à renovação da aliança do Senhor na eucaristia, bem como os estimula à caridade.

Da Liturgia, portanto, mas da Eucaristia principalmente, como de uma fonte, se deriva a graça para nós e com a maior eficácia é obtida aquela santificação dos homens em Cristo e a glorificação de Deus, para a qual, como a seu fim, tendem todas as demais obras da Igreja. ${ }^{8}$

Comentando o texto, vinte e cinco anos depois, o Papa João Paulo II enxerga a liturgia como fonte no fato de que, mormente nos sacramentos, "os fiéis vão beber abundantemente a água da graça, que mana do lado de Cristo crucificado". ${ }^{9}$ E completa: "ela é como a fonte da aldeia, à qual todas as gerações vêm beber a água sempre viva e fresca". ${ }^{10}$

Outra contribuição sobre o tema provém dos documentos produzidos pelas Conferências Gerais do Episcopado Latino-Americano. Medellín afirmou que "o gesto litúrgico não é autêntico se não implica um compromisso com a caridade"; ademais, a celebração, "para ser sincera e plena, deve conduzir tanto às várias obras de caridade e à ajuda mútua, como à ação missionária e às diversas formas de testemunho cristão". ${ }^{11}$ Puebla, outrossim, assinala que a liturgia impele os fiéis a testemunhar na vida e na missão; ${ }^{12} \mathrm{e}$, mais, que "a liturgia é também força em nosso peregrinar, para que se leve a bom termo, mediante o compromisso transformador da vida, a realização plena do Reino, segundo o plano de Deus". ${ }^{13}$ Aparecida, por seu turno, desvela o número 10 da Sacrosanctum Concilium nestas palavras: "a Igreja que a celebra [a eucaristia] é 'casa e escola de comunhão', onde os discípulos compartilham a mesma fé, esperança e amor a serviço da missão evangelizadora". ${ }^{14}$ Os três documentos identificam a liturgia como força impulsionadora que atua sobre os que dela participam na direção do cumprimento da missão cristã.

$\mathrm{Na}$ realidade, não se pode exagerar a estreita relação entre Liturgia e Missão, a primeira como fonte de vitalidade para a segunda, na própria teologia conciliar. Aquilo que veio a ser realçado nos documentos latino-americanos na verdade já podia ser vislumbrado na Sacrosanctum Concilium e nos demais textos originados do Concílio Vaticano II. Como sustenta López Martín ao celebrar o advento do Concílio, "à liturgia faltava algo fundamental para justificar seu papel na missão da Igreja" ${ }^{15}$ mas não mais, uma vez que tal lacuna foi preenchida pela Constituição Litúrgica. Alberto Beckhäuser, exaltando a Constituição como primeiro documento do Sagrado Concílio, atesta seu condão de mexer com as estruturas da Igreja e, em especial, sua teologia, espiritualidade, vocação e missão. ${ }^{16}$

Não é coincidência que, orientada pela Sacrosanctum Concilum, a Constituição Dogmática Lumen Gentium tenha confirmado que a participação no sacrifício eucarístico de Cristo seja a fonte e o centro de toda a vida cristã e salientado, como implicação eclesiológica, que os fiéis manifestam visivelmente a unidade do Povo de Deus quando são "alimentados pelo corpo de Cristo na Eucaristia". ${ }^{17}$ Nesse mesmo diapasão, o Decreto Ad Gentes sobre a atividade missionária da Igreja conclama a comunidade cristã a se tornar sinal da presença de Deus no mundo a partir do sacrifício eucarístico. $^{18}$

Portanto, é impossível voltar-se para a Sacrosanctum Concilium, no contexto dos documentos do Concílio Vaticano II que a desdobraram, sem essa perspectiva missiológica. Sobretudo na analogia da fonte, a Constituição Litúrgica eleva a liturgia como princípio gerador da força que revigora os fiéis em prol do desenvolvimento de sua missão no mundo. Como mais tarde corrobora Francisco, o zelo evangelizador brota, de fato, "de uma verdadeira santidade de vida, alimentada pela oração e

\footnotetext{
${ }^{8} \mathrm{SC} 10$.

${ }^{9}$ VQA 22.

${ }^{10}$ VQA 22.

${ }^{11} \mathrm{DM}$ 9.2.3.

${ }^{12}$ DP 938.

${ }^{13}$ DP 918.

${ }^{14}$ DAp 158.

${ }^{15}$ MARTÍN, L. J., No Espírito e na verdade, p. 326.

${ }^{16}$ BECKHÄUSER, A., Sacrosanctum Concilium, p. 10.

${ }^{17}$ LG 11.

${ }^{18}$ AG 15.
} 
sobretudo pelo amor à eucaristia". ${ }^{19}$ Vale acrescentar, o Pontífice retomou esse elemento em recente discurso aos monges da Confederação Beneditina, cujo amor pela liturgia foi elogiado como "água de uma nascente que irriga e fecunda" e alimenta "a capacidade de viver, pessoal e comunitariamente, o encontro com o Senhor Ressuscitado". ${ }^{20}$ A liturgia - e sua vivência apaixonada - é, por conseguinte, o ponto de partida e o combustível para a missão cristã.

\subsection{A Liturgia como ponto de chegada (cume)}

Na mencionada Vicesimus quintus annus, João Paulo II ilumina o sentido da liturgia como cume da vida da Igreja nestes termos: "toda a atividade da Igreja tende para a comunhão de vida com Cristo; e é na Liturgia que a Igreja manifesta e comunica aos fiéis a obra da Salvação, realizada por Cristo de uma vez para sempre". ${ }^{21}$ Segundo o Papa, há duas acepções pelas quais a liturgia é cume da vida da Igreja: a primeira diz respeito à culminação de algo que vem sendo realizado pela Igreja, e a segunda a algo que se presentifica na própria assembleia litúrgica. A atenção aqui repousará sobre primeiro o aspecto: o que vem antes da liturgia e nela culmina?

Por certo, a pergunta abre uma infinitude de possibilidades dos mais variados matizes teológicos, impossível de ser destrinchada aqui. Obviamente, o Papa não pretendeu restringir "toda a atividade da Igreja" à evangelização, mas permita-se focar a relação entre Missão e Liturgia, que certamente está incluída nesse conjunto de atividades da Igreja que tendem para a comunhão da vida com Cristo. Então, a pergunta pode ser reformulada: de que forma a liturgia poderia representar o ponto de chegada da ação missionária da Igreja? Para responder a essa questão, importa resgatar um conceito aventado por Francisco.

\section{Uma Igreja em saída (e também em retorno?)}

Sem dúvida, um dos temas que marca o pontificado de Francisco é o da "Igreja em saída". Na Evangelii Gaudium, o Papa reservou os itens 20 a 24 a esse assunto, começando por demonstrar como esse "dinamismo de saída que Deus quer provocar nos crentes" aparece constantemente na Palavra de Deus. ${ }^{22}$ Ele cita Abraão, Moisés, Jeremias e, por fim, Jesus, pela força de cujo "ide" todos somos chamados a uma nova "saída missionária", uma renúncia da própria comodidade visando alcançar todos os que precisam da luz do Evangelho. ${ }^{23}$

Em seguida, o Pontífice invoca o capítulo 10 do Evangelho de Lucas, o qual retrata a alegria do Evangelho experimentada pelos setenta e dois discípulos ao regressarem da missão. ${ }^{24}$ Pelo princípio da alegria, Francisco enlaça de maneira singular evangelização e liturgia. Como bem descreve o recente texto da Comissão Episcopal para a liturgia para a 56 Assembleia Geral de 2018, o Papa "parece querer unir a alegria da missão evangelizadora com a liturgia e seu estilo repleto da alegria do divino Espírito". ${ }^{25}$ Nesse pensamento, a alegria missionária, a qual foi experimentada pelos discípulos, é vivenciada por uma Igreja "em saída" enquanto comunidade de discípulos missionários que, ao final de sua missão, festejam o sucesso de sua evangelização. ${ }^{26}$ E explica:

A comunidade evangelizadora jubilosa sabe sempre "festejar": celebra e festeja cada pequena vitória, cada passo em frente na evangelização. No meio desta exigência diária de fazer avançar o bem, a evangelização jubilosa torna-se beleza na liturgia. A Igreja evangeliza e se evangeliza com a beleza da liturgia, que é também celebração da atividade evangelizadora e fonte dum renovado impulso para se dar. ${ }^{27}$

\footnotetext{
${ }^{19}$ EG 76.

${ }^{20}$ FRANCISCO, PP., Discurso aos Monges da Confederação Beneditina (19 abr. 2018).

${ }^{21}$ VQA 22.

${ }^{22} \mathrm{EG} 20$

${ }^{23} \mathrm{EG} 20$.

${ }^{24}$ EG 21.

${ }^{25}$ COMISSÃO EPISCOPAL PARA A LITURGIA, Liturgia e Evangelização, n. 5.

${ }^{26}$ EG 24.

${ }^{27} \mathrm{EG} 24$.
} 
Em outros termos, a alegria missionária repercute na beleza da liturgia. Não é apenas o fato de que a própria liturgia evangelize, como foi assinalado por João Paulo II no número 22 da Vicesimus quintus annus, naquela segunda acepção da metáfora do cume pela qual a Igreja manifesta e comunica aos fiéis a obra da Salvação. Tampouco como defende Ramos, para quem a liturgia evangeliza deste modo: "desenvolvendo festivamente a salvação anunciada, tornando-a presente na comunicação e no gozo, antecipando a realização total", ${ }^{28}$ ou, ainda, Beckhäuser:

A Liturgia constitui a maior epifania ou manifestação da Igreja. Ela mostra a Igreja aos que estão fora dela, como estandarte erguido diante das nações, a fim de que se estabeleça a verdadeira união entre os cristãos e todos sejam congregados até que haja um só rebanho e um só pastor. Podemos dizer, então, que a Igreja evangeliza, sobretudo, através da celebração da fé, através das ações litúrgicas. ${ }^{29}$

Certamente, essa função evangelizadora da liturgia, também engrandecida por Puebla,${ }^{30}$ merece toda a reflexão teológica e pastoral. No entanto, não parece ser esse o enfoque de Francisco na Evangelii Gaudium 21. Ali, a evangelização a ser considerada não é apenas aquela concomitante à celebração litúrgica e que flui de sua natureza. A evangelização festejada na liturgia é, também, uma atividade que a antecede, desenvolvida por uma Igreja em saída, a qual agora se acha reunida porque, antes, havia saído e retornou. A alegria obtida durante a "saída missionária", a qual contribui para o avanço do bem no mundo, repercute no ato cúltico e adiciona àquilo que já é, em si, uma festividade um motivo a mais de gozo espiritual.

Como salienta Ramos, "celebração" já quer dizer festa, um fenômeno festivo, "um gozo comum ou uma comunicação gozosa". ${ }^{31} \mathrm{Ou}$, como manifesta Puebla, a liturgia é "festa de comunhão eclesial". ${ }^{32}$ Se ela já é assim por essência, quanto mais na visão do Papa Francisco, para quem pode-se adicionar ainda mais alegria à liturgia na medida em que a Igreja se reúna para celebrar os avanços da missão. Daí a referência à passagem do Evangelho de Lucas constituir um esboço sugestivo dessa percepção. Nela, os discípulos, depois de terem saído em missão, retornam comemorando o fato de que os demônios se lhes submeteram, conforme a autoridade que Jesus lhes outorgara (Lc 9,1). Francisco vislumbra nesse regresso vitorioso dos discípulos uma nuance festiva que deve se fazer presente na celebração litúrgica.

No entanto, o alerta implicado ali é que tal alegria somente pode ser experimentada por uma Igreja composta de missionários que, atuantes no mundo, concorram jubilantes ao seu encontro com o Senhor na assembleia. Talvez aqui se explique por que alguns cristãos da atualidade tenham dificuldade em comprazer-se nas celebrações litúrgicas, às vezes reputadas como monótonas e cansativas. Seria porque tais cristãos não têm experimentado - ou o têm de forma tão insignificante que nem conseguem sentir - a alegria missionária durante a semana?

É bem verdade que, como salienta Triacca, neste mundo secularizado, o próprio ato de reunir-se em assembleia "já representa opção e testemunho". ${ }^{33}$ Todavia, se o que se espera de um discípulo missionário é que tão somente frequente as celebrações dominicais, tal expectativa ficaria muito aquém da alegria missionária expressa no reencontro dos discípulos com Jesus em Lc 10,17. Há festa na assembleia litúrgica porque, como afirma Aparecida, "a alegria da participação no ministério pascal de Jesus Cristo não é um sentimento artificialmente provocado nem um estado de ânimo passageiro", ${ }^{34}$ mas um que transforma a vida toda em vida eucarística. ${ }^{35} \mathrm{Ou}$ seja, para o cristão que se apresenta como um discípulo missionário, a alegria cúltica será a culminação da alegria existencial. Aquele que desfrutou do gozo da missão durante os dias que precederam o Dia do Senhor, o terá em plenitude na assembleia eucarística e, então, a beleza da liturgia será o sinal de uma experiência de encontro com

\footnotetext{
${ }^{28}$ RAMOS, M., Evangelização e Liturgia, p. 425.

${ }^{29}$ BECKHÄUSER, A., Sacrosanctum Concilium, p. 17.

${ }^{30}$ DP 924.

${ }^{31}$ RAMOS, M., Evangelização e Liturgia, p. 424.

${ }^{32}$ DP 918.

33 TRIACCA, A. M., Igreja e Liturgia, p. 578.

${ }^{34}$ DAp 17.

${ }^{35}$ DAp 251.
} 
Jesus Cristo vivo. ${ }^{36}$ A vida missionária cotidiana, a qual Francisco denomina "vida sacramental", ${ }^{37}$ pode ser considerada, dessa forma, uma trilha montanhosa que conduz ao pico do júbilo litúrgico.

Mas que ações o discípulo missionário desenvolve no curso da semana em sua jornada até o cume litúrgico? A resposta também é encontrada no número 24 da Evangelli Gaudium.

\section{Quatro ações antes do "festejar" litúrgico}

Consoante a Evangelii Gaudium 24, o festejar é a última de cinco ações de uma Igreja em saída. Antes de festejar - e, por que não?, para festejar - os cristãos devem 'primeirear', envolver-se, acompanhar e frutificar". ${ }^{38}$ Explique-se.

"Primeireiar" é tomar a iniciativa, "ir ao encontro, procurar os afastados e chegar às encruzilhadas dos caminhos para convidar os excluídos". ${ }^{39}$ O Pontífice recordou seu neologismo em homilia proferida em 2015, quando exortou os cristãos a, seguindo o exemplo de Jesus, serem proativos no amor como fruto de uma "fé que se fez vida, uma vida que se fez esperança e uma esperança que vos leva a 'primeirear' na caridade". ${ }^{40}$

A segunda ação, consequência da primeira, é envolver-se. Prossegue a Evangelii Gaudium 24:

Com obras e gestos, a comunidade missionária entra na vida diária dos outros, encurta as distâncias, abaixa-se - se for necessário - até à humilhação e assume a vida humana, tocando a carne sofredora de Cristo no povo. Os evangelizadores contraem assim o "cheiro das ovelhas", e estas escutam a sua voz. ${ }^{41}$

Seguem a terceira e a quarta ações:

Em seguida, a comunidade evangelizadora dispõe-se a "acompanhar". Acompanha a humanidade em todos os seus processos, por mais duros e demorados que sejam. Conhece as longas esperas e a suportação apostólica. A evangelização patenteia muita paciência, e evita deter-se a considerar as limitações. Fiel ao dom do Senhor, sabe também "frutificar". A comunidade evangelizadora mantém-se atenta aos frutos, porque o Senhor a quer fecunda. ${ }^{42}$

Pelo que se infere, somente depois de desincumbir-se dessas quatro atividades, a comunidade cristã, e o fiel individualmente, encontrarão na liturgia o ponto culminante de sua existência, aquela verdadeira festa espiritual que reproduza o encontro jubiloso dos discípulos com Cristo em Lc 10,17 e antecipe a reunião final com ele naquela "liturgia celestial que se celebra na cidade santa de Jerusalém, para a qual nos dirigimos como peregrinos". "Essas quatro ações formariam, assim, a trilha que culmina no pico da festividade litúrgica. Não é coincidência que, para concluir o parágrafo 24 , o Papa Francisco retome justamente a analogia da fonte para, de uma só vez, capturar o espírito conciliatório entre culto e missão proposto pela Sacrosanctum Concilium e completar o ciclo virtuoso entre saída e chegada da Igreja:

A comunidade evangelizadora jubilosa sabe sempre "festejar": celebra e festeja cada pequena vitória, cada passo em frente na evangelização. No meio desta exigência diária de fazer avançar o bem, a evangelização jubilosa torna-se beleza na liturgia. A Igreja evangeliza e se evangeliza com a beleza da liturgia, que é também celebração da atividade evangelizadora e fonte dum renovado impulso para se dar. ${ }^{44}$

\footnotetext{
${ }^{36}$ COMISSÃO EPISCOPAL PARA A LITURGIA, Liturgia e Evangelização, n. 5.

${ }^{37} \mathrm{EG} 28$.

${ }^{38}$ EG 24.

${ }^{39} \mathrm{EG} 24$.

${ }^{40}$ FRANCISCO, PP., Homilia do Santo Padre em Viagem Apostólica ao Equador, Bolívia e Paraguai.

${ }^{41}$ EG 24.

${ }^{42}$ EG 24.

${ }^{43}$ SC 8.

${ }^{44}$ EG 24, a ênfase é nossa.
} 
Não é demais repetir: "a evangelização jubilosa torna-se beleza na liturgia". ${ }^{45}$ O que é isso senão que a participação na alegria da missão é uma forma de preparação do fiel - quiçá a melhor delas -para a participação gozosa na celebração litúrgica?

Portanto, dizer que a liturgia é fonte e cume da vida da Igreja pode significar que a atuação missionária vibrante da Igreja no mundo, e dos fiéis em particular, é propelida pela participação ativa e consciente na celebração litúrgica, e que, num ciclo que se retroalimenta, o envolvimento autêntico dos cristãos no mistério que se celebra é dinamizado pela vivência missionária cotidiana, a qual, tendo em vista a alegria do retorno (Lc 10,17), enriquece a experiência litúrgica.

A liturgia, para o discípulo de Jesus Cristo, não pode representar um mero "rito cultual, mas uma espécie de 'gestualização crítica' da vida ou uma 'existencialização do culto" . ${ }^{46}$ Como salienta Triacca,

a renovação litúrgica pretenderia levar os fiéis participantes ao cerne da celebração, para que vivendo o que celebram, possam celebrar de modo autêntico o que vivem. O 'fluxo e o refluxo' entre a vida e a celebração deveriam reduzir e, no seu ponto máximo, anular o desvio, ou melhor, o desnível, existente em muitos fiéis entre 'celebração' e 'vida'. ${ }^{47}$

Aparentemente, esse "fluxo e refluxo" entre fonte e cume, entre ponto de partida e chegada, torna-se uma realidade ainda mais profícua e engrandecedora para aqueles fiéis que se colocarem, de fato, como discípulos missionários e, a partir do júbilo que lhes reserva o retorno da missão, tragam à assembleia litúrgica as ofertas provenientes da existência vivida sacramentalmente. Ousa-se afirmar, por conseguinte: é possível que uma participação mais qualitativa e quantitativa dos fiéis na liturgia dependa, em grande medida, de uma maior e melhor participação deles na missão cristã do dia a dia.

\section{Conclusão}

A comparação da liturgia como cume e fonte da vida da Igreja, extraída do número 10 da Sacrosanctum Concilium, tem sido celebrada como ilustração do espírito da renovação litúrgica proposta pelo Concílio Vaticano II. A liturgia como fonte a coloca como ponto de partida para a missão da Igreja e, como cume, como ponto de chegada. Nota-se, portanto, a estreita relação entre liturgia e missão, a qual tem sido aprofundada pelo Magistério recente.

Um dos temas centrais do pontificado de Francisco é o da "Igreja em saída", assunto a que se dedicam os números 20 a 24 da Evangelii Gaudium. No 21, o Pontífice invoca o capítulo 10 do Evangelho de Lucas, o qual retrata a alegria do Evangelho experimentada pelos discípulos ao regressarem da missão. Ali, Francisco vale-se da alegria como elo entre a evangelização e a liturgia. Segundo o Papa, a alegria missionária, a qual foi experimentada pelos discípulos, é vivenciada por uma Igreja "em saída" enquanto comunidade de discípulos missionários que, ao final de sua missão, festejam o sucesso de sua evangelização. ${ }^{48} \mathrm{E}$ concluiu, com riqueza ímpar: "a evangelização jubilosa torna-se beleza na liturgia". ${ }^{4}$

Francisco realça a ideia da liturgia como cume ao apontar a evangelização, que é nela festejada, como uma atividade que a antecede, desenvolvida por uma Igreja em saída, a qual agora está reunida porque havia saído e retornou. Com efeito, para a Evangelii Gaudium 21, a alegria experimentada na ação missionária, repercute na celebração ao adicionar-lhe um tom de comemoração, a exemplo do que ocorre na citada passagem de Lucas. Há festa na assembleia litúrgica porque, repita-se, "a alegria da participação no mistério pascal de Jesus Cristo não é um sentimento artificialmente provocado nem um estado de ânimo passageiro", ${ }^{50}$ mas um que transforma a vida toda em vida eucarística. ${ }^{51}$ Logo, a alegria cúltica pode ser entendida como a culminação da alegria existencial.

\footnotetext{
${ }^{45} \mathrm{EG} 24$.

${ }^{46}$ BOROBIO, D. A., Celebração da Igreja, p. 305.

${ }^{47}$ TRIACCA. A. M., Participação, p. 893.

${ }^{48} \mathrm{EG} 24$.

${ }^{49} \mathrm{EG} 24$

${ }^{50}$ DAp 17.
} 
Contudo, para que isso aconteça, continua a exortação apostólica, o discípulo missionário precisa desenvolver, numa trilha que conduz ao cume litúrgico, quatro ações: 'primeirear' - isto é, tomar a iniciativa - envolver-se, acompanhar e frutificar. ${ }^{52}$ Somente depois de desempenhá-las na vida cotidiana, a comunidade cristã, e o fiel individualmente, encontrarão na liturgia o ponto culminante de sua vida (Lc 10,17). Portanto, a célebre analogia conciliar da fonte e cume parece sugerir que a participação ativa e consciente na celebração litúrgica impulsiona a Igreja, e o fiel em particular, a uma atuação missionária vibrante; e, ao mesmo tempo, num ciclo de fluxo e refluxo entre vida e celebração, ${ }^{53}$ a participação jubilosa na missão outorga aos cristãos uma alegria singular que enriquece a experiência cúltica.

Conclui-se que uma participação mais qualitativa e quantitativa dos fiéis na liturgia pode estar condicionada, em grande medida, a uma maior e melhor participação deles na missão cristã do dia a dia. Em outros termos, a qualidade da celebração pública pode estar diretamente relacionada com a qualidade do culto particular daqueles que dela participam. ${ }^{54}$ Por conseguinte, o debate sobre os caminhos para uma maior participação dos fiéis na liturgia provavelmente permeie uma questão missiológica e pastoral, e não apenas de teologia ou prática litúrgicas. Desde que, na esteira da Sacrosanctum Concilium e do Magistério do Papa Francisco, a liturgia é o ponto de chegada e de partida de uma Igreja em saída e em retorno, e se, realmente, a alegria da celebração litúrgica alimentar e for alimentada pela alegria da evangelização, tudo parece indicar que missiologia e teologia litúrgica devam andar ombreadas, ajudando-se mutuamente com vista à completa implementação dos ideais de participação do Concílio Vaticano II, tanto na liturgia como na missão.

\section{Referências bibliográficas}

BECKHÄUSER, A. Sacrosanctum Concilium: texto e comentário. São Paulo: Paulinas, 2016. BOROBIO, D. A. Celebração da Igreja. São Paulo: Loyola, 1990. v.1.

CELAM. Medellín: A Igreja na atual transformação da América Latina à luz do Concílio. Petrópolis: Vozes, 1980.

CELAM. Puebla: a evangelização no presente e no futuro da América Latina. Petrópolis: Vozes, 1983.

CELAM. Documento de Aparecida: texto conclusivo da V Conferência Geral do Episcopado LatinoAmericano e do Caribe. Brasília: Edições CNBB; São Paulo: Paulus / Paulinas, 2008.

COMISSÃO EPISCOPAL PARA A LITURGIA. Liturgia e Evangelização: texto da Comissão Episcopal para a Liturgia para a 56 ${ }^{\mathrm{a}}$ AG 2018. Aparecida / SP: CNBB, 2018.

CONCÍLIO VATICANO II. Constituição Dogmática Sacrosanctum Concilium sobre a Liturgia. In: BECKHÄUSER, Alberto. Constituição do Concílio Vaticano II sobre a Sagrada Liturgia - Edição jubilar. Petrópolis, RJ: Vozes, 2013. p. 21-86.

CONCÍLIO VATICANO II. Ad gentes. AAS 58 (1966), n. 947-990.

CONCÍLIO VATICANO II. Lumen Gentium. AAS 57 (1965), n. 5-75.

FRANCISCO, PP. Evangelii Gaudium (24 de novembro de 2013). Disponível em: $<$ http://w2.vatican.va/content/francesco/pt/apost_exhortations/documents/papa-francesco_esortazioneap_20131124_evangelii-gaudium.html>. Acesso em: 12 nov. de 2018.

\footnotetext{
${ }^{51}$ DAp 251.

${ }^{52} \mathrm{EG} 24$.

${ }^{53}$ TRIACCA. A. M., Participação, p. 893.

${ }^{54}$ TIPPIT, S., Coração ardente, p. 112.
} 
FRANCISCO, PP. Homilia do Santo Padre em Viagem Apostólica ao Equador, Bolívia e

Paraguai (11 de julho de 2015). Disponível em:

$<$ http://w2.vatican.va/content/francesco/pt/homilies/2015/documents/papa-

francesco_20150711_paraguay-omelia-caacupe.html>. Acesso em: 07 dez. 2018.

FRANCISCO, PP. Discurso aos Monges da Confederação Beneditina (19 de abril de 2018). Disponível em: <http://w2.vatican.va/content/francesco/pt/speeches/2018/april/documents/papafrancesco_20180419_monaci-benedettini.html $>$. Acesso em: 21 nov. 2018.

JOÃO PAULO II, PP. Carta Apostólica Vicesimus quintus annus (4 de dezembro de 1988). Disponível em: <http://w2.vatican.va/content/john-paul-ii/it/apost_letters/1988/documents/hf_jpii_apl_19881204_vicesimus-quintus-annus.html>. Acesso em: 20 nov. 2018.

MARTÍN, L. J. No Espírito e na verdade: introdução teológica à liturgia. Petrópolis: Vozes, 1996. v. 1 .

MARINI, P. Quarantième anniversaire de la Constitution conciliaire sur la Liturgie. Disponível em: http://www.vatican.va/news_services/liturgy/2003/documents/ns_lit_doc_20031204_40concilium_fr.html. >. Acesso em: 14 dez. 2018.

RAMOS, M. Evangelização e Liturgia. In: SARTORE, D. TRIACCA, A. M. (Orgs.). Dicionário de liturgia. São Paulo: Paulus, 1992. p. 423-426.

TIPPIT, S. Coração ardente: uma chamada à santidade pessoal. 4. ed. Rio de Janeiro: JUERP, 1996.

TRIACCA. A. M. Igreja e Liturgia. In: SARTORE, D. TRIACCA, A. M. (Orgs.). Dicionário de liturgia. São Paulo: Paulus, 1992. p. 572-580.

TRIACCA. A. M. Participação. In: SARTORE, D. TRIACCA, A. M. (Orgs.). Dicionário de liturgia. São Paulo: Paulus, 1992. p. 886-904.

Diogo da Cunha Carvalho

Doutorando em Teologia pela Pontifícia Universidade Católica do Rio de Janeiro Docente na Faculdade Batista do Rio de Janeiro

Rio de Janeiro / RJ - Brasil

E-mail: prdiogocarvalho@hotmail.com

Recebido em: $14 / 12 / 18$

Aprovado em: 29/03/19 